\title{
Assessing and modeling economic and environmental impact of wheat nitrogen management in Belgium
}

\author{
B. Dumont a, b, d, *, B. Basso a, c, B. Bodson ${ }^{\text {d }}$, J.-P. Destain ${ }^{\text {d }}$, M.-F. Destain ${ }^{\text {b }}$ \\ a Dept. Geological Sciences, Michigan State University, East Lansing, MI, USA \\ b Dept. Biosystems Engineering, ULg - Gembloux Agro-Bio Tech, 5030 Gembloux, Belgium \\ ${ }^{\text {c } W . K . ~ K e l l o g g ~ B i o l o g i c a l ~ S t a t i o n, ~ M i c h i g a n ~ S t a t e ~ U n i v e r s i t y, ~ H i c k o r y ~ C o r n e r, ~ M I, ~ U S A ~}$ \\ d Dept. Agronomy, Bio-Engineering and Chemistry, ULg - Gembloux Agro-Bio Tech, 5030 Gembloux, Belgium
}

\section{A R T I C L E I N F O}

\section{Article history:}

Received 29 April 2015

Received in revised form

10 December 2015

Accepted 8 February 2016

Available online $\mathrm{xxx}$

\section{Keywords:}

Tactical nitrogen management

Climatic variability

Probability risk assessment

LARS-WG

Crop model

STICS

\begin{abstract}
A B S T R A C T
Future progress in wheat yield will rely on identifying genotypes and management practices better adapted to the fluctuating environment. Nitrogen $(\mathrm{N})$ fertilization is probably the most important practice impacting crop growth. However, the adverse environmental impacts of inappropriate $\mathrm{N}$ management (e.g., lixiviation) must be considered in the decision-making process. A formal decisional algorithm was developed to tactically optimize the economic and environmental $\mathrm{N}$ fertilization in wheat. Climatic uncertainty analysis was performed using stochastic weather time-series (LARS-WG). Crop growth was simulated using STICS model. Experiments were conducted to support the algorithm recommendations: winter wheat was sown between 2008 and 2014 in a classic loamy soil of the Hesbaye Region, Belgium (temperate climate). Results indicated that, most of the time, the third $\mathrm{N}$ fertilization applied at flag-leaf stage by farmers could be reduced. Environmental decision criterion is most of the time the limiting factor in comparison to the revenues expected by farmers.
\end{abstract}

(c) 2016 Elsevier Ltd. All rights reserved.

\section{Introduction}

Future improvement in wheat yield will rely on the identification of genotypes and/or management practices that are best adapted to the environment (Chenu et al., 2011). However, the complexity of the genotype-environment-management practice interactions (GEM) requires setting up extensive and costly field experiments. Because resources are limited, in practice, breeders typically select new cultivars that are suited to a specific environment (Semenov and Halford, 2009). For practical reasons, such experiments are usually limited to (i) the geographical area targeted by the breeding programme and (ii) the climatic conditions encountered by the plant during the selection program. Furthermore, (iii) the selection is typically performed under management conditions in which sufficient nutrient levels are supplied to the crop. Incorporating a new trait into a crop takes $10-12$ years, and only then it will be known if it has been effective in improving yield in the various environments (Asseng and Turner, 2007).

\footnotetext{
* Corresponding author. 2, Passage des Déportés, 5030 Gembloux, Belgium.

E-mail addresses: bdumont@msu.edu, benjamin.dumont@ulg.ac.be (B. Dumont).
}

The environment has two main components that induce variability, respectively soil and weather. Within a given field, differences in texture, structure, and organic matter may induce high variability. These soil characteristics greatly affect the soil moisture content and the available water capacity for plants. They not only drive water stress but also, in turn, impact soil nutrient availability (Basso and Ritchie, 2005). Concerning climatic variables, it has long been demonstrated that both the average values of weather variables and the sequencing of weather events greatly impact the dynamics of crop growth (Semenov and Porter, 1995). Interactive stresses may have a greater impact on the final value of crop characteristics of interest (e.g., grain yield) than individual stresses (Riha et al., 1996). For these reasons, the importance of an accurate characterization of soil and weather inputs data increases as the environment becomes more limiting in terms of plant growth and development (Weiss and Wilhelm, 2006).

Concerning the management of crops, nitrogen $(\mathrm{N})$ fertilization is probably one of the most important practices. The optimum $\mathrm{N}$ fertilization is known to vary within the same field and with each growing season as a result of the heterogeneity of soil properties, as well as inter- and intra-annual climatic patterns (Basso et al., 2012b). Furthermore, the decision-making process linked to $\mathrm{N}$ 
management remains complex because even if a spatial map of soil properties exists, the decision regarding the amount of $\mathrm{N}$ fertilizer to apply must be made without any prior knowledge of future weather conditions (Basso et al., 2011b). Consequently, experimentally determining how plant characteristics, either individually or in combination, affect crop performance under a wide range of growing conditions is an intractable task (Hoogeboom et al., 2004). In such a context, determining the optimum amount of and the most appropriate timing for $\mathrm{N}$ fertilizer is a challenge (Makowski et al., 2001).

Crop modeling approaches are powerful tools to allow a more comprehensive analysis of real-life processes (Sinclair and Seligman, 1996). Crop simulation models, such as STICS (Brisson et al., 2009), SIRIUS (Semenov et al., 2007), and SALUS (Basso et al., 2012a), are computerized representations of crop development, growth, and yield elaboration. They simulate the functions and impacts of the continuum of soil-plant-atmosphere systems (Hoogeboom et al., 2004). They integrate the current understanding of crop growth derived from physiological studies and phenotypic characteristics measured in various environments (Semenov et al., 2009). By dissociating processes that closely interplay in the real world and cannot be always observed directly, crop models have become engineering tools that extend the potentialities of field experimentation (Casadebaig and Debaeke, 2011). By highlighting gaps in our knowledge, they can be used to guide the direction of fundamental research (Semenov et al., 2007). Furthermore, they have demonstrated to be efficient in assisting in analyzing and deconvoluting any combination of complex GEM interactions (Asseng and Turner, 2007; Chenu et al., 2011). For these reasons, crop models have already proven to be well-suited to supporting decision-making and planning in agriculture (Basso et al., 2011a; Ewert et al., 2011). However, to properly address new environmental issues, the purpose of crop models needs to be widened by encapsulating them in modeling platform (Bergez et al., 2014; Brown et al., 2014) or by surrounding them with appropriate analysis algorithms (Dumont et al., 2014a; Talbot et al., 2014).

Crop models can help to improve farmers' decisions by assessing the probability that a certain outcome will occur under specific management practices and the given pedo-climatic conditions of a certain field (Basso et al., 2011a, 2012b; Houlès et al., 2004). Dumont et al. (2013, 2014a, 2015a) have recently demonstrated how stochastically generated weather can be used to quantify the uncertainty that impacts on yield and $\mathrm{N}$ leaching in order to optimize $\mathrm{N}$ fertilization. However, until now, this approach had remained limited to strategic management.

The objective of this study is to optimize $\mathrm{N}$ management at the intra-annual level by modeling the within-season environmentmanagement interactions. Winter wheat (Triticum aestivum L.) growth was simulated under multiple $\mathrm{N}$ strategies and a panel of environments. An environment was here defined by a given soil type and a wide variety of climatic conditions. Stochastically generated climate time series were derived so that the most advantageous and disadvantageous climatic variable combinations could be explored. Such probabilistic climatic scenarios were coupled with historical records made between sowing and the flagleaf stage. Multi-objective decision criteria were computed to optimize the economic return of the assessed $\mathrm{N}$ practices while minimizing the adverse environmental impacts associated with potentially inappropriate $\mathrm{N}$ rates.

\section{Material and methods}

\subsection{Field experiment}

Between 2008 and 2014, field experiments were conducted to study intra- and inter-annual wheat growth patterns (T. aestivum L.) under the agro-environmental conditions of the Hesbaye region (classic loam soil type) in Belgium (temperate climate) and under variable $\mathrm{N}$ management practices (Table 1 ). The cultivar was usually sown between mid-October and mid-November and harvested between very late July and mid-August. The measurements considered for simulation purposes were the results of four repetitions for date, nitrogen level, and crop season. The repetitions were performed on experimental blocks $(2 \mathrm{~m} \times 6 \mathrm{~m})$ that were implemented according to a completely randomized block distribution to ensure measurement independence. During this experiment, biomass (total dry matter and grain yield), plant $\mathrm{N}$ uptake, and soil $\mathrm{N}$ content were measured twice a month during the growing season, from mid-February until harvest. The measurements were carried out on dried samples corresponding to the sampling of three adjacent $50 \mathrm{~cm}$ rows separated from $14.6 \mathrm{~cm}$. Once per month, the biomass samples were crushed, and their $\mathrm{N}$ content was analyzed in a laboratory. Once every two weeks, alternating with the sampling of the biomass, the soil $\mathrm{N}$ content was measured between 0 and $150 \mathrm{~cm}$ in $15 \mathrm{~cm}$ soil layers. Because they are time- and/or money-consuming, LAI measurements and soil $\mathrm{N}$ measurements were only performed for Exp. 1 and Exp. 4.

During the first four years (2008-2012), crop response was analyzed under seven $\mathrm{N}$ fertilization strategies, varying the rate and timing of fertilizer application, as described in the first part of Table 1 . Total amounts of $\mathrm{N}$ between 0 and $240 \mathrm{~kg} \mathrm{~N}^{-1}$ were applied to explore the full response curve of the crop to $\mathrm{N}$. In Belgium, the current $\mathrm{N}$ fertilizer management practice consists of splitting a total of $180 \mathrm{~kg} \mathrm{~N}$ ha ${ }^{-1}$ into three equal fractions $\left(60 \mathrm{~kg} \mathrm{~N} \mathrm{ha}^{-1}\right.$ ) and applying them at the tillering (Zadoks stage $23-$ ZS 23), stem extension (ZS 30), and flag-leaf (ZS 39) stages (Zadoks et al., 1974). This practice is presented as Experiment Four (Exp. 4) in Table 1. During the last two years (2012-2014), for reasons detailed and explained in Section 2.4, new experimental N strategies were designed based on the Belgian farmers' current practices (Table 1, second part). For Exp. 8 to Exp. $10,60 \mathrm{~kg} \mathrm{~N}^{-1}$ were applied at the tiller (ZS 23) and stem extension (ZS 30) stages, but increasing fractions were applied at the flag-leaf stage (ZS 39), from 0 to $90 \mathrm{~kg} \mathrm{~N} \mathrm{ha}^{-1}$ in $30 \mathrm{~kg} \mathrm{~N} \mathrm{ha}^{-1}$ steps.

Table 1

Details of the field trials to study the crop response to variable $\mathrm{N}$ management, where different amounts and timing of $\mathrm{N}$ applications were investigated.

\begin{tabular}{|c|c|c|c|c|c|c|}
\hline \multicolumn{7}{|c|}{ Fertilization level $\left[\mathrm{kg} \mathrm{N} \mathrm{ha}^{-1}\right]$} \\
\hline Exp. \# & Tiller & $\mathrm{T}-\mathrm{S}$ & Stem exten. & Flag leaf & Total & Season \\
\hline Zadoks & 23 & 29 & 30 & 39 & & \\
\hline Exp. 1 & 0 & 1 & 0 & 0 & 0 & $2008-2014$ \\
\hline Exp. 2 & 30 & i & 30 & 60 & 120 & \\
\hline Exp. 3 & 1 & 60 & 1 & 60 & 120 & \\
\hline Exp. 4 & 60 & 1 & 60 & 60 & 180 & \\
\hline Exp. 5 & 1 & 90 & 1 & 90 & 180 & \\
\hline Exp. 6 & 60 & 1 & 60 & 120 & 240 & \\
\hline Exp. 7 & 1 & 120 & 1 & 120 & 240 & \\
\hline Exp. 8 & 60 & 1 & 60 & 0 & 120 & $2012-2014$ \\
\hline Exp. 9 & 60 & i & 60 & 30 & 150 & \\
\hline Exp. 10 & 60 & I & 60 & 90 & 210 & \\
\hline
\end{tabular}




\subsection{Model calibration and validation}

The STICS crop growth model (STICS V6.9) used in this study has been described in detail in several papers (Brisson et al., 2003, 2009). The model simulates the carbon dynamic, which is impacted by water and $\mathrm{N}$ stresses in the soil-plant-atmosphere system on a day-by-day basis (Palosuo et al., 2011). It requires the usual daily weather data inputs (i.e., minimum and maximum temperatures, total radiation, and total rainfall). According to the formalisms considered to compute potential and actual evapotranspiration, vapor pressure and wind speed may also be needed.

The STICS model calibration and validation were performed for the first 4 years of the database, as described in the previous section. Three criteria regularly used in crop modeling were used to judge the quality of the model, namely root mean square error (RMSE), Nash-Sutcliffe Efficiency (NSE), and normalized deviation (ND) (Beaudoin et al., 2008; Brisson et al., 2002; Dumont et al., 2014b). The calibration process was performed with the OptimiSTICS package (Wallach et al., 2011), in particular using the DREAM Bayesian sampling algorithm (Dumont et al., 2014b; Vrugt et al., 2009).

The parameters involved in the phenology, leaf area development, biomass growth and grain filling were optimized to better represent the Belgian cultivars (Dumont et al., 2014a, 2015a). The remaining parameters of the species were fixed at the suggested default values (Brisson et al., 1998). To correctly simulate the stresses induced by climatic conditions and to calculate the potential and the actual evapotranspiration, the resistive approach proposed by Shuttleworth and Wallace (Shuttleworth and Wallace, 1985) was preferred to the empirical Penman approach (Penman, 1948), both options being available in the STICS model.

To correctly calibrate the model's response to the simulated water and $\mathrm{N}$ stresses, the parameters were calibrated using the $\mathrm{N}$ treatments in Exp. 1 and Exp. 4 of the field trial (Table 1) for the three first crop seasons, 2008-09, 2009-10, and 2010-11. The model was then validated for all the other combinations' treatment years, i.e., Exp. 2, 3, 5, 6, and 7 for the three first years and Exp. 1 to Exp. 7 for crop season 2012-13.

More detail about the procedure and the results obtained can be found in Dumont et al. (Dumont et al., 2014a, 2014b, 2015a).

\subsection{Probability risk assessment using stochastically generated weather}

The reference weather station at Ernage (Observation network of Belgium's Royal Meteorological Institute - RMI - http://www. cra.wallonie.be/fr/bulletin) had made meteorological records since 1980 . Solar radiation, precipitation, vapor pressure, wind, and temperature data are available. The station is located $2 \mathrm{~km}$ from the experimental field. The complete 33-years (1981-2014) weather database (WDB) was used in this study in order to provide the inputs for the crop model.

Weather scenarios were stochastically derived from the Ernage WDB using the LARS-Weather Generator (WG) (Racsko et al., 1991; Semenov and Barrow, 1997). First, the daily maximum, minimum, mean, and standard deviation values of each climatic variable; the frequency distributions for rain; and the seasonal frequency distributions for the wet and dry series of observed climatic events were computed to characterize the experimental site. In a second step, on the basis of this representative parameter set, the LARSWG was used to generate a set of stochastic synthetic weather time-series (SWTS) that have the same statistical characteristics as the observed weather data (Semenov and Barrow, 2002). As demonstrated by the author, long weather sequences are usually required for risk assessment because the longer the time period of simulated weather used, the more the risk assessment will cover the range of potential weather events. As recommended by Lawless and Semenov (2005), 300 SWTS were used in this study to perform the probability risk assessment.

The stochastically-generated climatic set could then be input into the STICS crop model. Proceeding in such a way ensures the exploration of new combinations of weather variables, which can lead to simulated stress conditions that have not previously been observed within the field but are based on local climatic conditions (Dumont et al., 2013, 2015b).

\subsection{Numerical nitrogen management}

One way to increase yield and grain quality and to reduce $\mathrm{N}$ leaching is to deliver $\mathrm{N}$ when it is needed by the plant (Semenov et al., 2007). In that way, in Belgium, farmers used to provide $\mathrm{N}$ in sufficient and reasonable quantities $\left(60 \mathrm{~kg} \mathrm{~N} \mathrm{ha}^{-1}\right)$ at the tiller, stem extension, and flag leaf stages, which relate to Zadok stages 23,30 , and 39, respectively. In recent studies, Dumont et al. (2014a, 2014c, 2015b) successfully transposed the theory of yield distribution analysis (Day, 1965; Kyveryga et al., 2013) onto the study of crop model simulations. They demonstrated that the probability of achieving yields greater than the mean of the corresponding distribution was the highest when Belgian farmers' most typical $\mathrm{N}$ rate was applied. However, this strategy may be impacted by intraannual variability in climatic conditions and can be reconsidered at the within-season level.

In wheat, before the anthesis stages (ZS69), the detrimental impact of climatic conditions can generally be mitigated, to some extent, simply by the ability of the culture to compensate for it. By example, lower plant density rates due to intense winter conditions can be compensated for by producing a larger number of tillers. In the same way, a lower number of tillers could be compensated for by a higher number of grains per ear if climatic conditions allow for this. As discussed by Dumont et al. (2014c, 2015b), in terms of endseason yield prediction, as long as the final number of grains has not been fixed, the uncertainty in grain yield prediction caused by climatic variability remains very high.

The elaboration of grain yield is a complex phenomenon. The number of grains is set by the plant between flowering (ZS 50) and the end of anthesis (ZS 69), and it is driven by prevailing climate conditions and stresses. Once the number of grains has been fixed, grain yield will be limited by grain filling rates in terms of both carbohydrates and $\mathrm{N}$ exportation. This will be driven by the climatic conditions and nutrient availability between anthesis and maturity.

Therefore, in order to give the crop the maximum chance to achieve great yields and to avoid early $\mathrm{N}$ stresses that could impact yield much later in the season, it was decided to fix the first two $\mathrm{N}$ applications according to the usual practice (i.e., $60 \mathrm{~kg} \mathrm{~N} \mathrm{ha}^{-1}$ ). Various $\mathrm{N}$ levels were then applied as the third $\mathrm{N}$ application, from $0 \mathrm{~kg} \mathrm{~N} \mathrm{ha}^{-1}$ to $120 \mathrm{~kg} \mathrm{~N} \mathrm{ha}^{-1}$ (Table 2). This way of proceeding,

Table 2

Fertilization calendar and rates for simulated nitrogen management practices.

\begin{tabular}{|c|c|c|c|c|}
\hline \multicolumn{5}{|c|}{ Fertilization rate (in $\mathrm{kg} \mathrm{N} \mathrm{ha}^{-1}$ ) } \\
\hline Treat. \# & Tiller & Stem ext. & Flag leaf & Total \\
\hline Zadoks & 23 & 30 & 39 & \\
\hline M.60-1 & 60 & 60 & 0 & 120 \\
\hline M.60-2 & 60 & 60 & 10 & 130 \\
\hline M.60-3 & 60 & 60 & 20 & 140 \\
\hline M.60-4 & 60 & 60 & 30 & 150 \\
\hline$\ldots$ & $\ldots$ & $\ldots$ & $\ldots$ & $\ldots$ \\
\hline M.60-13 & 60 & 60 & 120 & 240 \\
\hline
\end{tabular}


presented in Dumont et al. (2015a), is referred to as 'modulo-60 management (M60-X)'. To validate these simulations, new field experiments were performed between 2012 and 2014 (Exp. 8, 9 and 10 of Table 1).

\subsection{Agronomical, economic and environmental decision criteria}

Considering the current economic situation, maximizing grain yield is not always a relevant strategy, and farmers' revenues must remain the focus. Therefore, grain selling price and the cost linked to $\mathrm{N}$ purchase were integrated within a unique economic criterion. As a first approach to $\mathrm{N}$ management, the optimal quantity of $\mathrm{N}$ fertilizer to apply could thus be determined on the basis of the marginal net revenue (MNR, Eq. (1)), as the rate maximizing this function (Basso et al., 2012a; Houlès et al., 2004):

$M N R=\left(Y_{N} \cdot G_{P}\right)-\left(N \cdot N_{P}\right)$

where MNR is the marginal net revenue $\left(€ \mathrm{ha}^{-1}\right), \mathrm{Y}_{\mathrm{N}}$ is the grain yield (ton ha $\left.{ }^{-1}\right), G_{P}$ is the grain price $\left(€ \operatorname{ton}^{-1}\right), \mathrm{N}$ is the total amount of fertilizer applied during the season $\left(\mathrm{kg} \mathrm{N} \mathrm{ha}^{-1}\right)$, and $\mathrm{N}_{\mathrm{P}}$ is the price of $\mathrm{N}\left(€ \mathrm{~kg} \mathrm{~N}^{-1}\right)$. Table 3 summarizes the grain selling prices and $\mathrm{N}$ costs observed during field experiments.

In Europe, in 1991, the European Community issued several directives aimed at reducing water pollution caused by nitrates from agricultural sources (EC-Council Directive, 1991). The Nitrate Directive 91/676/EEC was only transposed into Walloon law in 2002 under the Sustainable Nitrogen Management in Agriculture Program (PGDA) (Vandenberghe et al., 2011). In addition, a survey system has been put in place to control $\mathrm{N}$ leaching in sensitive areas. The nitrogen available for leaching (NAL), which is defined here as the soil nitrogen content observed in the $0-90 \mathrm{~cm}$ soil profile after harvest, is used as a control criterion. Reference NAL thresholds are established each year on the basis of the NAL observed within 35 farms that have been framed by a supervisory structure since 2002. Each year, these farms received fertilization recommendations and field management practices (such as sowing a catch crop, for example). On this basis, each year, for a given crop and a given preceding culture, the reference NAL thresholds are defined as the 75th percentile of the reference observations. Annually, at least 3\% of Walloon farmers are audited, and measurements taken in three of their fields are compared to references. If the evaluation is negative, next year, the farmers will be guided by the supervisory structure, but they have no obligation to follow the recommendations. However, if during two successive years they obtain negative evaluations, they are subjected to a diminution of the subsidies they receive.

While mostly successful, the problem with such a system is that the NAL references are establish a posteriori from the crop season. For farms being audited the first year, there are thus higher chances that the NAL might be over the threshold. Alternatives to and/or improvements in the system would be highly valuable. In that way, in order to optimize $\mathrm{N}$ management within the season while

Table 3

Grain selling prices and N costs.

\begin{tabular}{|c|c|c|}
\hline \multirow[t]{2}{*}{ Season } & $\mathrm{G}_{\mathrm{p}}$ & $\mathrm{N}_{\mathrm{p}}$ \\
\hline & [eur/ton] & [eur/ton] \\
\hline S.2008-09 & 125 & 165 \\
\hline S.2009-10 & 210 & 160 \\
\hline S.2010-11 & 215 & 245 \\
\hline S.2011-12 & 185 & 275 \\
\hline S.2012-13 & 200 & 275 \\
\hline S.2013-14 & 130 & 300 \\
\hline
\end{tabular}

considering environmental issues, the methodology proposed by Basso et al. (Basso et al., 2011a) and later used by Dumont et al. (2015a) on stochastically generated climates was used in this paper. For each climatic probability level and for each $\mathrm{N}$ level, the approach consisted of plotting the MNRs as a function of the NAL in a 2D graph. On this basis, the optimal $\mathrm{N}$ practices were those that both maximized the MNRs while minimizing the NAL.

\subsection{Setting up a tool to tactically manage nitrogen}

Using a crop model to develop a tactical approach to $\mathrm{N}$ management implies that it should both be able to optimize the $\mathrm{N}$ amount, as well as determine the timing of fertilization. This section details the concepts lying behind the tool, describing first how the dates of $\mathrm{N}$ application are automatically determined, and then how the decision-making tool operates to support the optimization of $\mathrm{N}$ fertilizer at ZS39. Fig. 1 schematizes the global procedure that was developed.

For any given climatic year, the model was first run considering only the first $\mathrm{N}$ application, performed at the tiller stage (ZS 23). For the reasons detailed in the previous section, the rate was set to $60 \mathrm{~kg} \mathrm{~N} \mathrm{ha}^{-1}$ and $\mathrm{N}$ was applied every year at the same Julian day ([JD]). Within our trials, ZS 23 usually appeared at the same moment of the year, quite independently of the sowing date. The value of 445 was calculated to be the mean for the observed date during the field experiments.

Within the STICS model, the phenological stage closest to stem extension (ZS 30) and predicted by the model is IAMF, i.e., the day at which the rate of leaf area development is maximal. Following an iterative process, for each cultural season, the model was first run considering only the first $\mathrm{N}$ application at ZS 23. Model results were then used to predict the second date of $\mathrm{N}$ application according to the simulated IAMF stage. Thirdly, once the date was predicted, the algorithm automatically applied a second rate of $60 \mathrm{~kg} \mathrm{~N} \mathrm{ha}^{-1}$.

Finally, within the STICS model, IFLO, i.e. the day at which flowering occurs (ZS 50), is the stage predicted by the model that is the closest to the flag leaf stage (ZS 39). As previously done, model simulations relying on the real climatic data and the two first $\mathrm{N}$ fractions were used to determine ZS 39 according to the simulated IFLO occurrence.

Once ZS 39 occurrence was determined for each growing season, the algorithm entered into the real decision-making part of the system. Simulations were conducted, considering that the real climatic data occurred from sowing until ZS 39 and that different scenarios may occur between ZS 39 and maturity. The impact of 300 SWTS was assessed. Similarly, the impacts of increasing N fractions, ranging from 0 to $120 \mathrm{~kg} \mathrm{~N} \mathrm{ha}^{-1}$ in $10 \mathrm{~kg} \mathrm{~N} \mathrm{ha}^{-1}$ steps and applied at ZS 39, were evaluated. In other words, this part of the algorithm allows the analysis of environment-management interactions: $(i)$ the management is defined here by variable $\mathrm{N}$ fertilizer rates, and (ii) the environment is defined by variations in climatic conditions. Finally, the algorithm computed different criteria based on either economic or environmental considerations (cfr. previous section). The decision rule consisted of selecting the $\mathrm{N}$ practice that optimized the criterion/criteria.

\subsection{Validating the decision support system}

On the basis of the algorithm depicted at Section 2.6, the approach's validity was demonstrated as follow. In a first phase, the ability of the model to predict the dates of $\mathrm{N}$ fertilizer application for ZS 30 and ZS 39 was assessed in comparison to the field experiments. We then briefly described the results of the $\mathrm{N}$ fertilization calendar automatically determined by the algorithm for the overall historical climatic records, where the planting date and the 


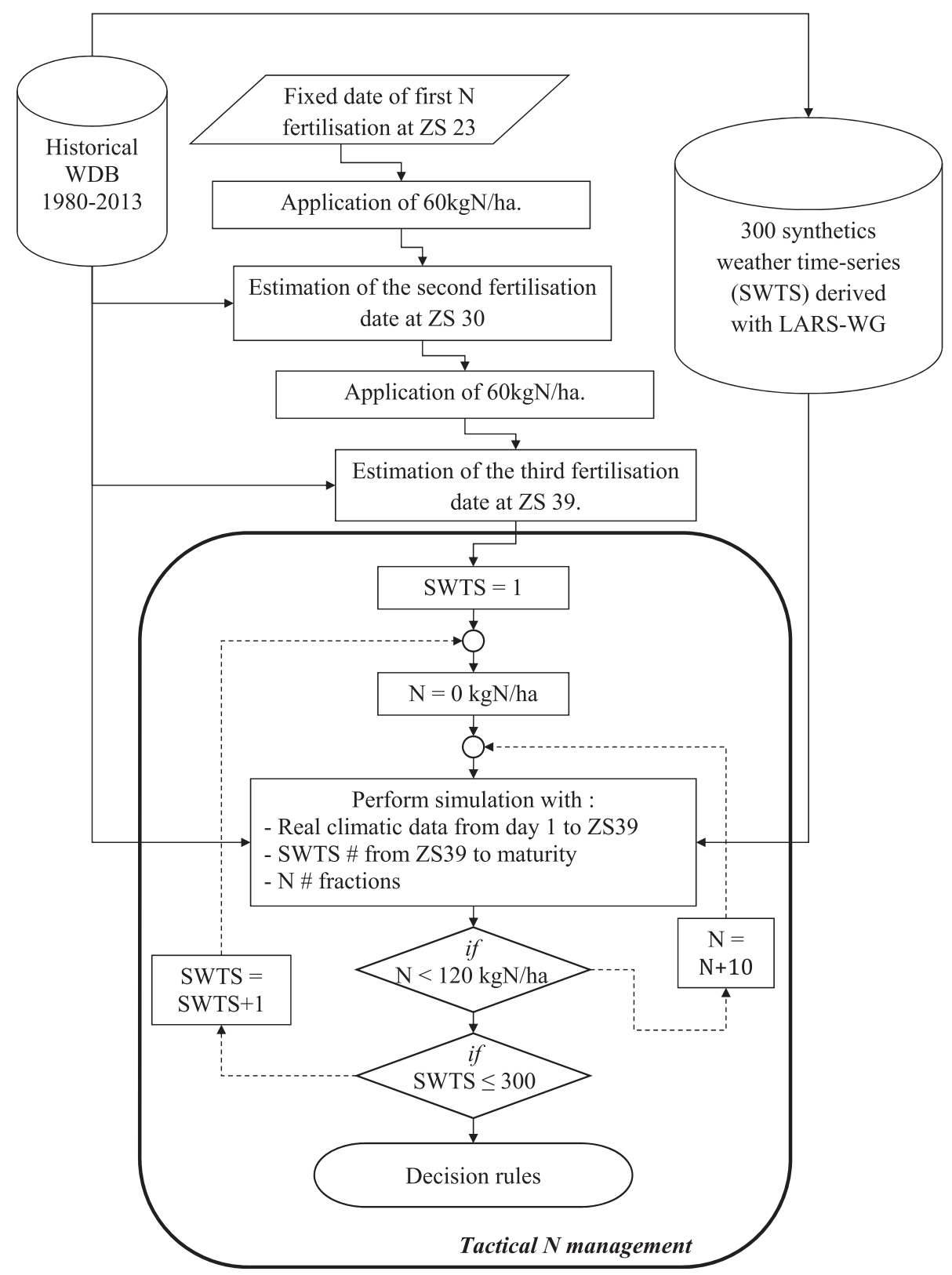

Fig. 1. Organization chart of the algorithm developed to evaluate the tactical N optimization tool.

date of the first $\mathrm{N}$ application (ZS 23) were fixed this time.

In a second phase, the ability of the algorithm to tactically manage $\mathrm{N}$ fertilization was validated on the case study, and more specifically for the crop season 2012-13 and 2013-14 for which the experimental design had been adapted (Table 1). In this phase, the real planting dates, the observed dates for $\mathrm{N}$ fertilizer applications and the real climatic data occurring between sowing and ZS 39 were considered and inputted into the model. Probabilistic weather projections were used between ZS39 and maturity to generate the yield prediction. Result analysis consisted to confront the predicted yields to the field observations. The MNRs criteria were then used to determine the optimal $\mathrm{N}$ rates over the case study. Special attention was given to analyze the $\mathrm{N}$ recommendation for crop season 2012-13 and 2013-14.

Finally, once the model has been proven efficient to predict $\mathrm{N}$ fertilization calendar and to optimize $\mathrm{N}$ management, in the third and last phase, the entire algorithm was retroactively used over the entire historic climatic database. The fertilization was automatically driven by the simulations, and the algorithm was used to optimize $\mathrm{N}$ management at the flag-leaf stage (ZS 39). MNR and NAL were used as decision criteria.

\subsection{Software availability}

STICS is a free software, available by downloading at http:// www6.paca.inra.fr/stics_eng, including a set of default parameters covering general parameters and specific plant parameters. The software program OptimiSTICS is a library of Matlab functions (The MathWorks Company, Natick, Massachusetts, USA) divided into several sub-packages, including multi-simulation and parameter optimization, that (over-)writes inputs and parameter values, calls the STICS executable function, and reads the model outputs. The OptimiSTICS codes were obtained upon request by the authors (emmah_web@paca.inra.fr). The core of the tactical N management 
algorithm was designed as Matlab functions interfaced with OptimiSTICS.

\section{Results and discussions}

\subsection{Crop model quality}

The differences between simulated model outputs and measured field and plant variables are shown at Fig. 2 for the validation dataset. The criteria for model quality for the calibration
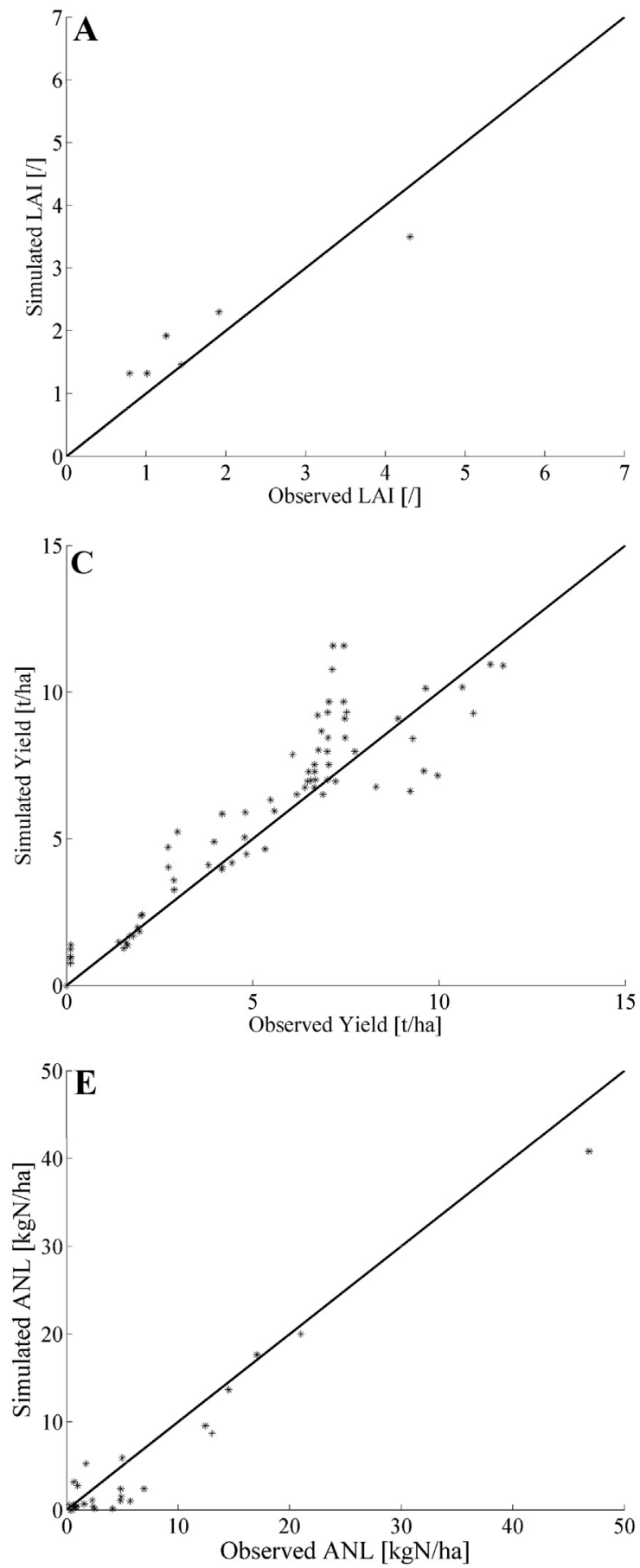

and validation phases are presented at Table 4 .

The usual threshold (Beaudoin et al., 2008; Dumont et al., 2014b) expected in crop modeling for NSE (NSE > 0.5) was largely met during the calibration and validation steps for LAI, total biomass, grain yield, and plant $\mathrm{N}$ uptake (Table 4). A detailed evaluation of the STICS crop model accuracy and robustness can be found in Coucheney et al. (2015), where the author reported similar criteria for RMSE, NSE and ND.

However, while the STICS model simulated plant $N$ uptake particularly well, the NSE criterion for ANL was characterized by a
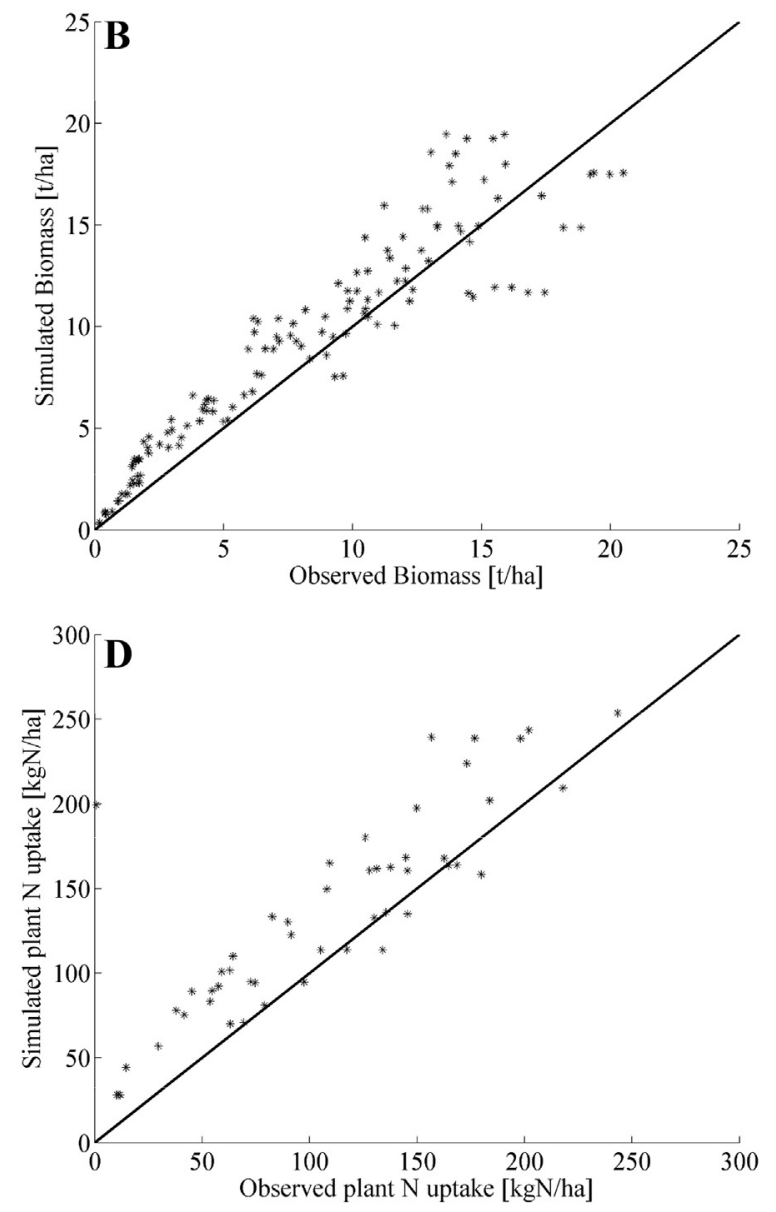
validation dataset. 
Table 4

Results of the model evaluation.

\begin{tabular}{|c|c|c|c|c|c|c|}
\hline \multirow[t]{3}{*}{ Variable } & \multicolumn{3}{|c|}{ Calibration } & \multicolumn{3}{|c|}{ Validation } \\
\hline & RMSE & NSE & ND & RMSE & NSE & ND \\
\hline & [unit] & {$[/]$} & {$[/]$} & [unit] & {$[/]$} & {$[/]$} \\
\hline LAI $\left[\mathrm{m}^{2} \mathrm{~m}^{-2}\right]$ & 0.58 & 0.81 & -0.01 & 0.52 & 0.81 & -0.10 \\
\hline Biomass $\left[\mathrm{t} \mathrm{ha}^{-1}\right]$ & 2.00 & 0.86 & -0.07 & 2.1 & 0.83 & -0.13 \\
\hline Grain yield $\left[\mathrm{t} \mathrm{ha}^{-1}\right]$ & 1.57 & 0.74 & -0.11 & 2.0 & 0.57 & -0.17 \\
\hline Plant $\mathrm{N}$ uptake $\left[\mathrm{kg} \mathrm{N} \mathrm{ha}^{-1}\right]$ & 28.75 & 0.80 & -0.20 & 42.74 & 0.48 & -0.26 \\
\hline ANL $\left[\mathrm{kg} \mathrm{N} \mathrm{ha}^{-1}\right]$ & 10.78 & -0.47 & 0.17 & 5.44 & 0.72 & 0.05 \\
\hline
\end{tabular}

negative value in the calibration phase. As reported by Constantin et al. (Constantin et al., 2012) for the same simulated output, the negative efficiency characterized the difficulty the model experienced in attempting to capture all the variability in the soil mineral $\mathrm{N}$ dynamic. In the validation phase, the model successfully simulated soil nitrogen content at the end of the season. More discussions of the simulations results and what may have caused the negative NSE values for ANL can be found in Dumont et al. (2014a).

As can be observed in Fig. 2 and confirmed by the negative ND criteria, the model tended to slightly over-estimate the observations. However, except for plant N uptake, the ND values were close to or below the expected threshold of $|\mathrm{ND}|<0.15$. Based on the results, it was concluded that the overall model quality was ensured, which allowed it to be used for prediction purposes.

\subsection{Automatic prediction of the fertilization calendar}

The days when N was applied at ZS 30 and ZS 39 during the field experiments were compared with the predicted IAMF and IFLO stages. The best fit between the simulations and the observations was obtained when, on average, 8 days were added to the predicted IAMF stage and when 15 days where subtracted from the predicted IFLO stage. These results are presented in Fig. 3. The 8 days that needed to be added to the IAMF stage were justified by the planning of actual agricultural operations. Once ZS 30 has been observed within the fields, the operation is scheduled and performed as quickly as possible. However, the fertilizer application

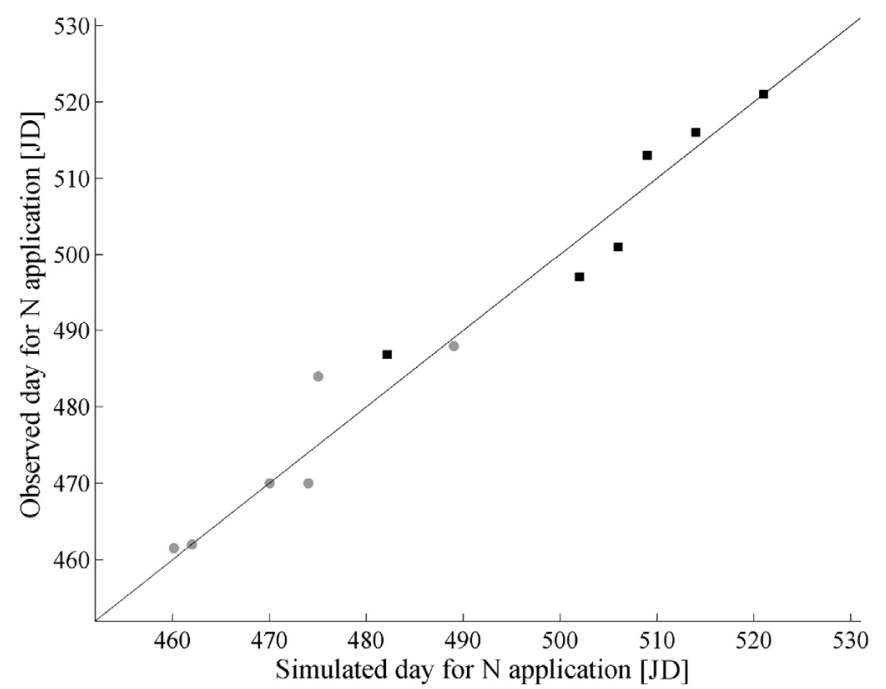

Fig. 3. Simulated day for the application of $N$ vs. the day at which $N$ was actually applied in the field. Days are expressed in Julian days [JD]. Grey dots represent the ZS 30 (०) and black squares represent the ZS $39(\boldsymbol{\square})$. Data represents the best fit between observations and a given number of day around stages IAMF ( +8 days) and IFLO ( -15 days) predicted by the model. could be delayed according to climatic conditions (rainy events, field practicability, etc.) or other priorities in the management (pest treatment, growth regulator, etc.). The 15 days that had to be subtracted from the IFLO stage occurrence date was in good agreement with our field observations, in which the flag-leaf stage was usually observed 2 weeks before flowering.

On this basis, the model was then used to predict ZS 30 and ZS 39 based on the 33-year climatic database. The results, ranked by the day of flag-leaf appearance, are presented in Fig. 4. As defined within the algorithm, the tiller stage (ZS 23) was systematically imposed at JD 445. The length of the growing cycles between ZS 23 and ZS 39 varies between 51 days and 81 days. A similar tendency was observed between the cumulated distribution of the flag-leaf stage's occurrence and the corresponding stem extension stages (ZS 30). However, according to the various climatic conditions used as inputs for the model, shorter cycles in ZS23-39 did not necessarily led to shorter cycles in ZS23-30, and vice versa, highlighting the importance of intra-year variability for wheat growth.

\subsection{Evaluating the decision support system over the case study}

To validate the decision support system, the tactical $\mathrm{N}$ optimization tool was used under following options: (i) observed climatic data were used as climatic inputs between sowing and flag-leaf, (ii) the dates of $\mathrm{N}$ application were inputted in the model as they were applied in the field, (iii) the modulo-60 $\mathrm{N}$ rates were simulated at these dates, and (iv) the probabilistic climatic data were applied between observed flag leaf and harvest. Fig. 5 presents the results of the grain yield simulation for the 2012-13 and 2013-14 seasons based on the probabilistic simulations run for 300 synthetic time series and for each $\mathrm{N}$ fraction level applied at the flag-leaf stage.

The graphical representation proposed by Dumont et al. (2014a) was adapted in this study to project the 3D response surface in a 2D space. The grain yields were ranked according to a cumulative distribution function corresponding to increasing favorable climatic conditions. The yield ranking was performed for each $\mathrm{N}$ level, and then, the yields were represented in the 2D space for each climatic probability level, ranging from 1 to $99 \%$ in $5 \%$ steps, and according to the increasing $\mathrm{N}$ fractions applied at the flag-leaf stage. The simulated end-season yields reported at Fig. 5 represented the potential yield of the crop under all possible future scenarios

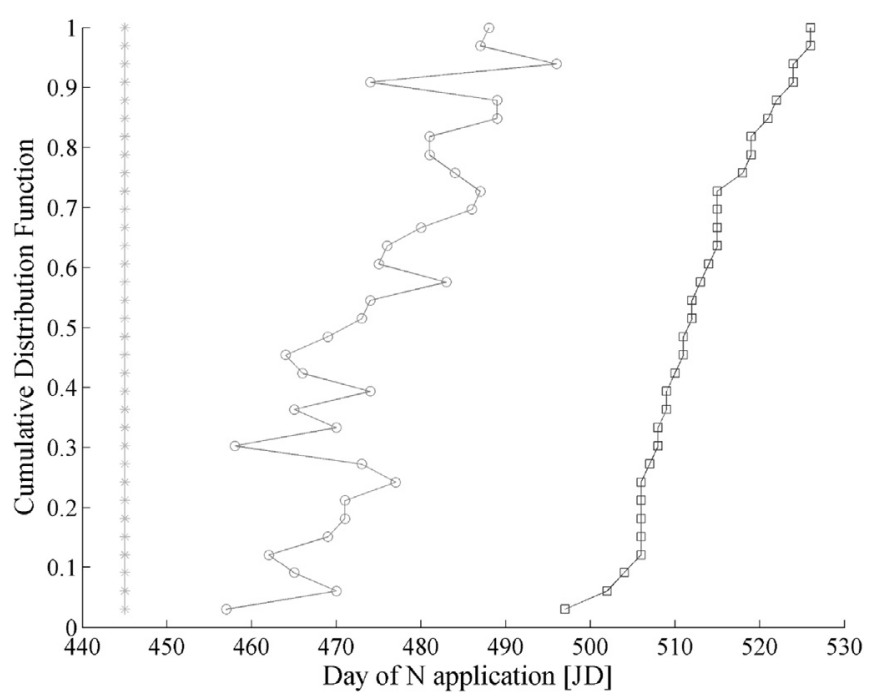

Fig. 4. Distributions of the simulated day for the ZS 23 (light grey star line,_*_), ZS 30 (middle grey dot line, -0-) and ZS 39 (black square line, - $\square$-). The results are ranked according to the cumulative distribution of the flag leaf stage occurrence. 

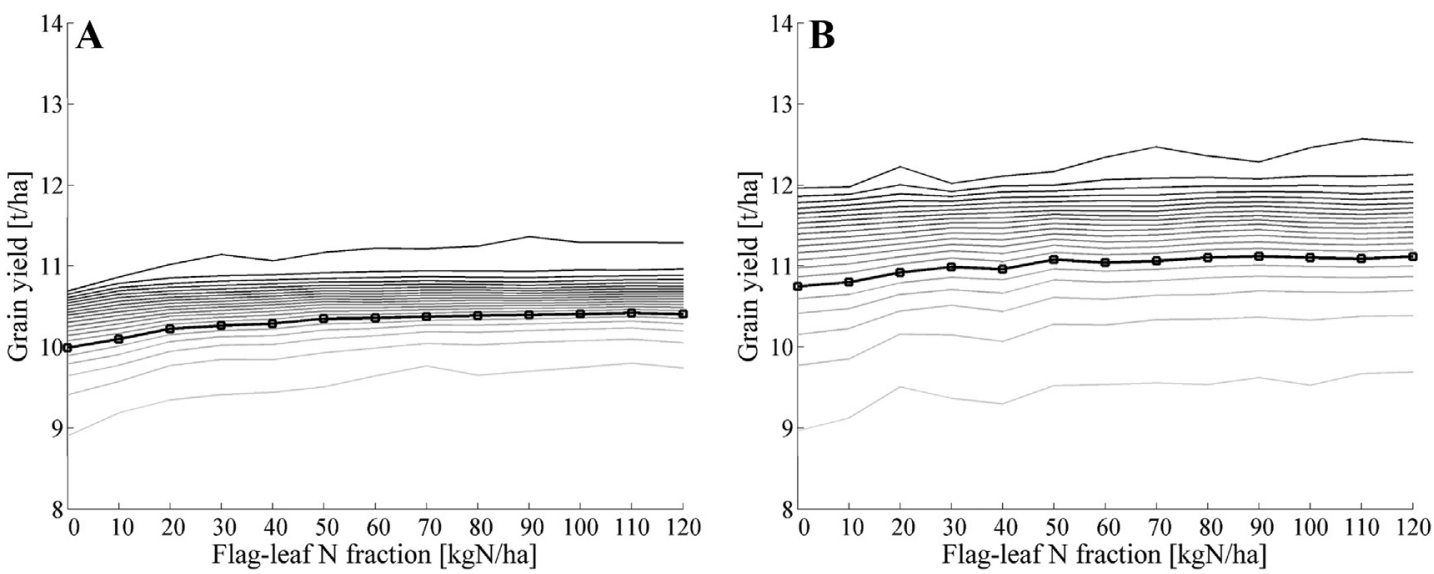

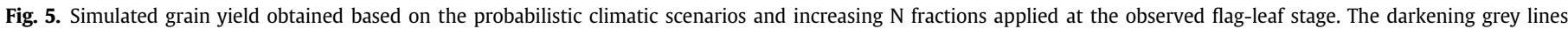

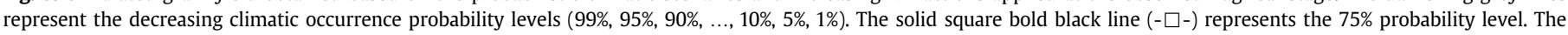
graphs stand respectively for the seasons 2012-2013 (A) and 2013-2014 (B).

occurring after flag-leaf stage.

Upon reading the graphs, an immediate conclusion could be drawn. When one is focused solely on third $\mathrm{N}$ fraction's optimization, the impact of weather conditions is much higher than the impact of $\mathrm{N}$ level. Similar observations were reported by Martre et al. (Martre et al., 2007), who investigated crop response to climate and variable $\mathrm{N}$ rates. Specifically, for each climatic probability level, after an initial increase in yield when 0 to $30 \mathrm{~kg} \mathrm{~N} \mathrm{ha}^{-1}$ are provided to the crop, the curves are characterized by a low level of response to $\mathrm{N}$ management. Thus, the increases in yield varied markedly depending on the expected future climatic conditions.

Moreover, the impact on end-season grain yield for past real climatic conditions that occurred between sowing and ZS 39 can be seen via the spreading on the y-axis of the probability curves. The range of the remaining yield potential is an indicator of the severity of the earlier stress that the crop encountered during its past growth, which may affect its future growth.

As discussed in Basso et al. (2012b) and Dumont et al. (2014a), one must select the simulated yield value that will be reached in at least 3 years out of 4 . This occurrence frequency corresponds to the probability level $75 \%$, represented by the square bold black line. The simulated yield values obtained at this probability level were compared to the observations made during the field experiments for the crop seasons 2012-13 and 2013-14, during which the $\mathrm{N}$ fraction applied at the flag-leaf stage was modulated. Therefore, the following observations are presented: $60-60-0 \mathrm{~kg} \mathrm{~N}^{-1}$ : Exp. 8 vs. M60-1; 60-60-30 $\mathrm{kg} \mathrm{N}$ ha $^{-1}$ : Exp. 9 vs. M60-4; $60-60-60 \mathrm{~kg} \mathrm{~N}^{-1}$ : Exp. 4 vs. M60-7; 60-60-90 $\mathrm{kg} \mathrm{N}^{-1}$ : Exp. 10 vs. M60-10; $60-60-120 \mathrm{~kg} \mathrm{~N}^{-1}$ : Exp. 6 vs. M60-13, with reference to Tables 1 and 2. The results are presented in Fig. 6. The relative difference between the means for the observations and the simulations was $6.5 \%$ for the $2012-13$ crop season and $1.0 \%$ for the 2013-14 crop season.

It can be concluded that the $75 \%$ probability level was highly relevant for the last two years of experiments. A concomitant analysis of Figs. 5 and 6 allowed us to conclude that the real climatic conditions that occurred after ZS 39 and up to the harvest were very close to climatic occurrence with the lowest probability. Indeed, Fig. 5 suggests that at a shorter return time to favorable climatic conditions, grain yields were higher. The consideration of a higher simulated yield would have thus reduced the differences between the observations. However, at ZS 39, no one could have known the upcoming future weather conditions. Given the low relative difference in mean yield between the simulations and the

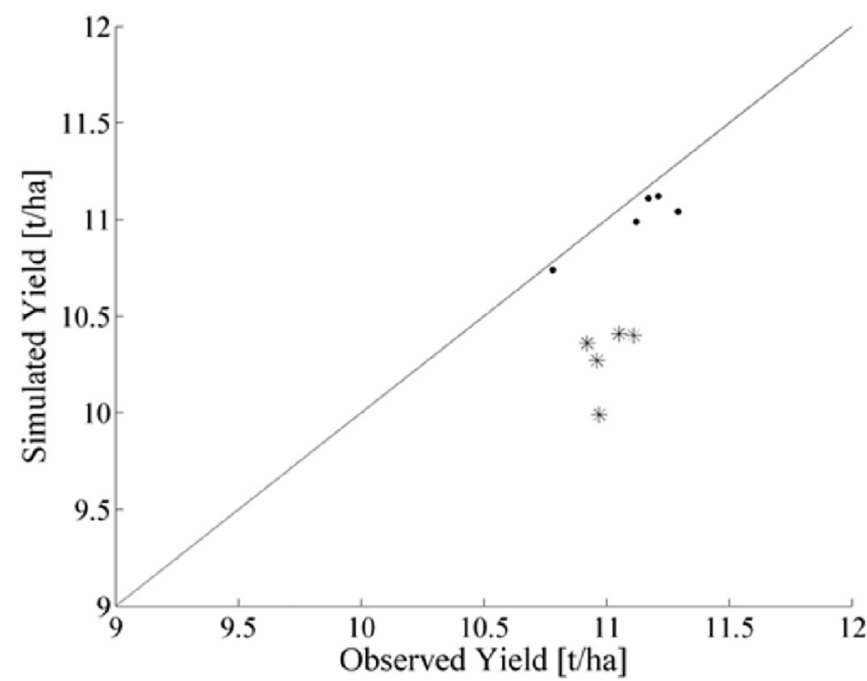

Fig. 6. Measured grain yield versus simulated grain yield at $75 \%$ probability level using the stochastic approach. Stars $\left(^{*}\right)$ represents the season $2012-13$ and dots $(\bullet)$ represents the season 2013-14. The results are plot for the couples of observations corresponding to the modulation of third $\mathrm{N}$ fractions applied at flag-leaf as detailed in Tables 1 and 2.

observations and considering the principle of precaution, the probability level of $75 \%$ indicated that a probability risk assessment should be performed for yield prediction.

\subsection{Analysis of the marginal net revenues over the case study}

On the basis of the grain selling prices and $\mathrm{N}$ costs presented in Table 3, the MNRs were computed for the different crop seasons (between S.2008-09 to S.2013-14). Fig. 7 presents the 3D response surfaces of the MNRs computed as a function of $\mathrm{N}$ fertilization practices (Table 2) and drawn out the 300 synthetic climatic scenarios for three contrasted years, respectively the crop seasons 2008-09, 2010-11, and 2012-13. As observed, the 3D MNR surfaces exhibited totally different patterns. Given the fact that the 300 synthetic weather time series used as projections between ZS 39 and harvest are similar for each season, the differences in the presented MNRs are thus impacted by two main components: (i) the prices associated to grain selling and $\mathrm{N}$ fertilizer costs and (ii) the simulated grain yields. These latter depend themselves on (a) 

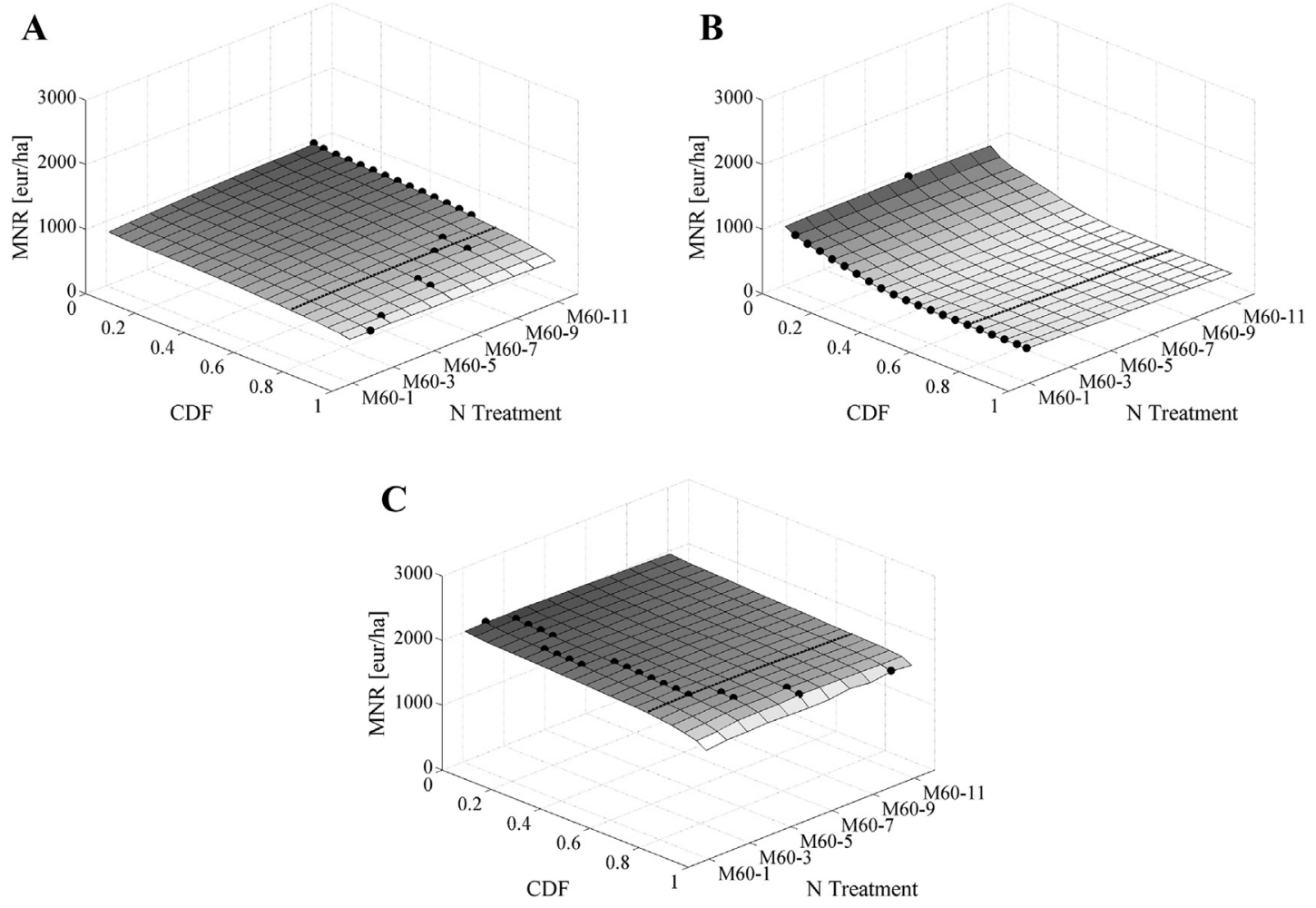

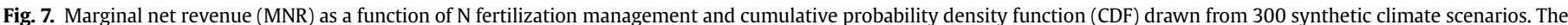

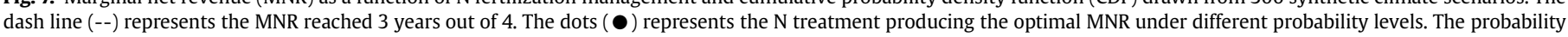
levels represented correspond to 1\%, 5\%, 10\%, .., 95\%, 99\%. The graphs stand respectively for the seasons $2008-09$ (A), 2010-11 (B) and 2012-13 (C).

the occurrence day of ZS 39 (and flowering) and (b) the subsequent slight differences in the projected climatic conditions between ZS 39 and maturity; and (c) the part of grain filling issued from biomass reallocation. Both (a) and (c) are impacted by the actual growing conditions prevailing between sowing and ZS 39 and independently driven each season by the observed climatic conditions.

For each climatic probability level, the corresponding optimal $\mathrm{N}$ rate can be highlighted. These rates were represented by black dots. The probability level of $75 \%$ was, in each case, represented by the dashed bold black line. Again, following Basso et al. (2012b) and Dumont et al. (2015a), without any knowledge of upcoming weather, one appropriate way to optimize $\mathrm{N}$ management is to select the rate that will outperform the others at least $75 \%$ of the time.

In such way, the optimal $\mathrm{N}$ practice should have been fixed respectively at $70 \mathrm{~kg} \mathrm{~N} \mathrm{ha}^{-1}$ in 2008-09 (Fig. 7), $60 \mathrm{~kg} \mathrm{~N}^{-1}$ in 2009-10, $0 \mathrm{~kg} \mathrm{~N} \mathrm{ha}^{-1}$ in 2010-11 (Fig. 7), $90 \mathrm{~kg} \mathrm{~N} \mathrm{ha}^{-1}$ in 2011-12, $20 \mathrm{~kg} \mathrm{~N} \mathrm{ha}^{-1}$ in 2012-13 (Fig. 7), and $10 \mathrm{~kg} \mathrm{~N} \mathrm{ha}^{-1}$ in 2013-14 (Fig. 7). These recommendations were in close accordance with the observations made at the end of each crop season, considering the climatic conditions that really occurred between ZS 39 and maturity and the consequent yield achieved.

In particular, within the refined experimental design for the crop seasons 2012-13 and 2013-14, at the time of the harvest, it was observed that the $\mathrm{N}$ practices that optimized the MNR were respectively $60-60-0 \mathrm{~kg} \mathrm{~N}^{-1}$ and $60-60-30 \mathrm{~kg} \mathrm{~N}^{-1}$. At ZS 39 , around the 20th of May, the algorithm had recommended the application of $60-60-20 \mathrm{~kg} \mathrm{~N}^{-1}$ and $60-60-10 \mathrm{~kg} \mathrm{~N} \mathrm{ha}^{-1}$. In both cases, the algorithm had correctly anticipated the reduction of the $\mathrm{N}$ fraction to be applied at the flag-leaf stage as compared to the farmers' typical practice of $60-60-60 \mathrm{~kg} \mathrm{~N} \mathrm{ha}^{-1}$.
Using a simpler probabilistic risk assessment approach to strategically optimize $\mathrm{N}$ for maize, Basso et al. (2012b) found a similar tendency to reduce $\mathrm{N}$ application when MNRs were computed and the $75 \%$ level was considered. In accordance with our observations, Asseng et al. (2012) found that $\mathrm{N}$ applications on wheat should be reduced when the MNR was computed for dryer seasons.

\subsection{The impact of decision rules}

Section 3.4 showed how the MNR could be computed and used as a decision criterion in optimizing $\mathrm{N}$ practice. However, considering current European and national legislation, economic interest cannot be the sole criterion considered. The NALs were simulated and used as environmental decision criteria. Following Basso et al. (2011a), the optimal $\mathrm{N}$ fraction was considered to be that which simultaneously maximized the MNR and minimized the NAL.

For this section, to make the predictions uniform, the dates at which N should be applied at ZS 30 and 39 were automatically determined using the algorithm. Then, the 300 synthetic time series were used to stochastically simulate the end-season yields and optimize $\mathrm{N}$ management within each season (Fig. 1). As a first assessment, the MNRs were computed for the 33 crop seasons using similar grain selling prices and $\mathrm{N}$ costs, which were fixed here at 200 and 300 euros ton ${ }^{-1}$, respectively (close to what was observed in 2012-13). For the 1980-81 and 2008-09 crop seasons, the results are illustrated in Fig. 8 for all climatic probability levels. Fig. 9 presents the same results but focuses on the $50 \%, 60 \%$, and $75 \%$ probability levels.

With decreasing probability of climatic occurrence, the NALs were reduced, while the MNRs increased. In both presented cases, it is interesting to notice how with decreasing probability level, the curve evolved from mostly flat to mostly erect. At very high 

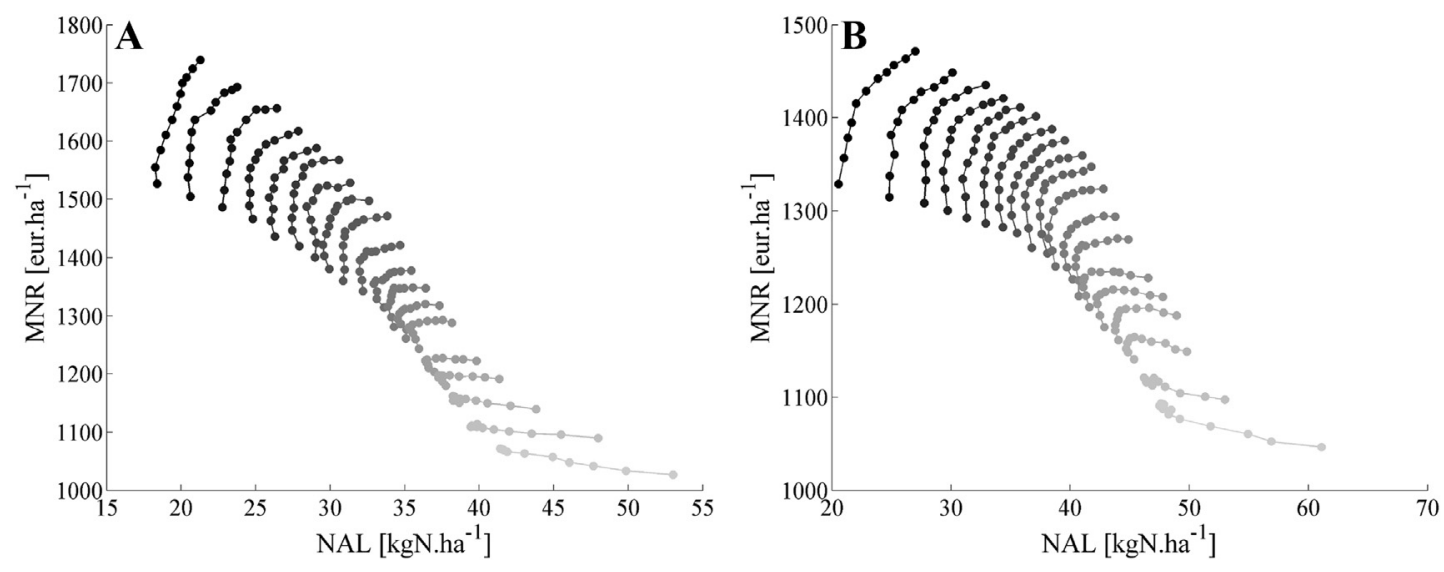

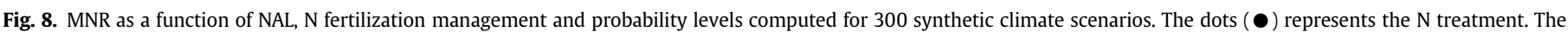
darkening grey lines represent the decreasing probability levels $(95 \%, 90 \%, \ldots, 10 \%, 5 \%)$. The graphs stand respectively for the seasons $1980-81$ (A) and $2008-09$ (B).
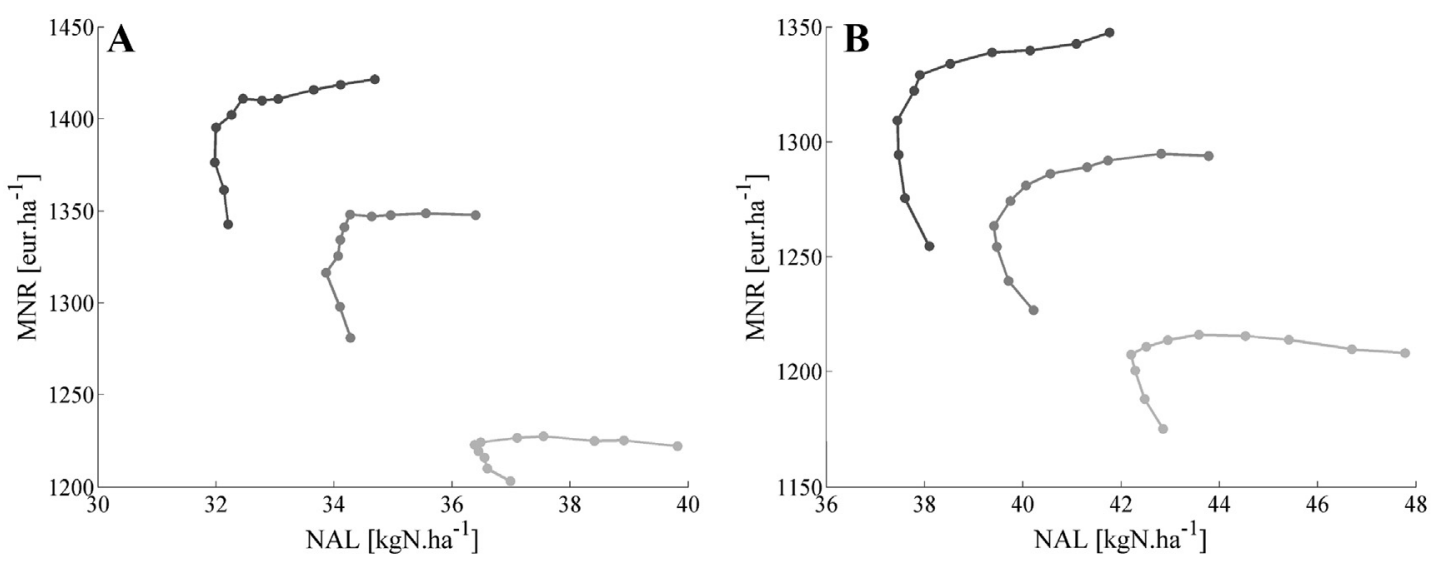

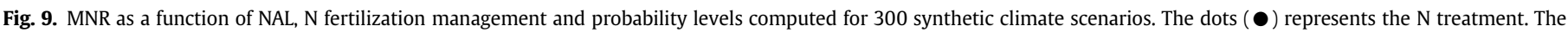

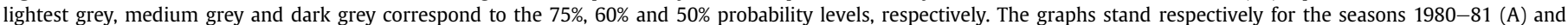
2008-09 (B).

probability levels (lightest grey lines), the MNR tends to decrease with $\mathrm{N}$ practice, while the NAL rises. In contrast, at very low probability levels (darkest grey lines), the NAL not only slightly increased with $\mathrm{N}$ practice but the MNR also clearly improved.

The optimal $\mathrm{N}$ was then determined for each crop season and climatic probability level. To determine which $\mathrm{N}$ rate minimized NAL while maximizing MNR, the ratio of MNR to NAL was computed for each crop season and probability level, and the best $\mathrm{N}$ rate was the one that optimized this ratio. For the 1980-81 season (left graph of Fig. 9), the optimal $\mathrm{N}$ was between 20 and $40 \mathrm{~kg} \mathrm{~N} \mathrm{ha}^{-1}$ at $75 \%$ and $60 \%$. At a $50 \%$ probability level, a unique $\mathrm{N}$ optimum occurred at $30 \mathrm{~kg} \mathrm{~N}^{-1}$. For the 2008-09 season, the optimal $\mathrm{N}$ rate equaled $30 \mathrm{~kg} \mathrm{~N} \mathrm{ha}^{-1}$, whatever the probability level was $(50 \%, 65 \%$, or $75 \%)$. This conclusion was not immediate based on the different shapes exhibited by the three curves.

Fig. 10 summarizes the optimal $\mathrm{N}$ rate for the 33 cropping seasons when the decision criteria consisted of maximizing either the MNR (as described in Section 3.4) or the MNR/NAL ratio. Only the optimal $\mathrm{N}$ fraction at $75 \%$ climatic probability were considered in both cases and reported via the curves. As can be observed, 20 to $30 \mathrm{~kg} \mathrm{~N} \mathrm{ha}^{-1}$ could be saved annually when considering the environmental criteria. In 11 out of 33 years, the MNR decision criterion would lead to $\mathrm{N}$ not being applied at the flag-leaf stage. Considering the environmental constraints implies that in 17 years out of 33 (i.e., in 1 year out of 2 ), less than $10 \mathrm{~kg} \mathrm{~N} \mathrm{ha}^{-1}$ should have been

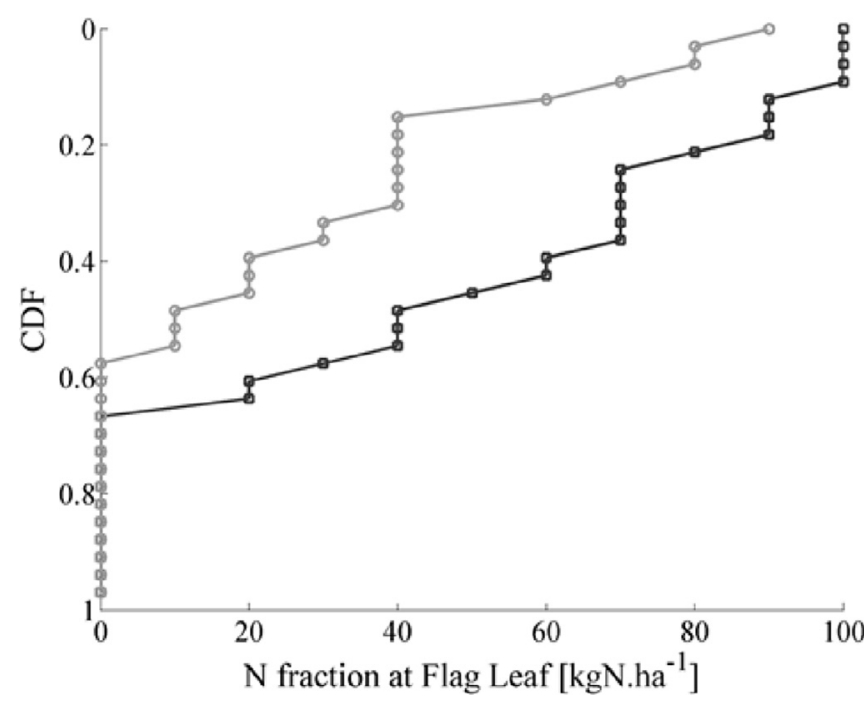

Fig. 10. Cumulative Distribution Function (CDF) of the optimal $N$ fraction that had to be applied at flag-leaf stage when the decision criteria is MNR (solid square black line $-\square-$ ) or MNR/NAL ratio (solid circle grey line $-0-$ ). The criteria where computed considering 200 eur ton ${ }^{-1}$ as grain selling price and 300 eur ton ${ }^{-1}$ for $\mathrm{N}$ costs. 
applied. Applying the Belgian farmers' usual practice $\left(60-60-60 \mathrm{~kg} \mathrm{~N} \mathrm{ha}^{-1}\right)$ or more is only interesting in 15 out of 33 years, (i.e., a bit less than 1 years out of 2 ) when only MNR is considered. The probability was decreased to 5 years out of 33 when the environment was a part of the decision.

\subsection{The impact of market prices}

Fig. 11 showed similar results under other economical conditions, considering, on the one hand, a grain selling price and $\mathrm{N}$ cost that were fixed at 200 eur ton ${ }^{-1}$ and 165 eur ton ${ }^{-1}$, respectively, which was similarly to the 2009-10 crop season, and on the other hand, a grain selling price and $\mathrm{N}$ cost fixed at 130 eur ton $^{-1}$ and 300 eur ton ${ }^{-1}$, respectively, which was similar to the 2013-14 crop season. To some extent, the conclusions drawn when considering environmental constraints remained similar: in approximately 1 year out of 2 , it would be recommended to apply less than $10 \mathrm{~kg} \mathrm{~N} \mathrm{ha}{ }^{-1}$. The MNR/NAL ratio is always the limiting criterion in terms of $\mathrm{N}$ application.

It also appeared that when the grain selling price was very low considering the $\mathrm{N}$ costs, the prioritization of pure financial interest led to a drastic diminution of the $\mathrm{N}$ quantity that should be applied each year (right graph). The MNR and MNR/NAL ratio criteria recommended similar N levels. However, when the grain selling price is high and when $\mathrm{N}$ costs were low, as in 2009-10 (left graph), the difference between the two curves reached $50 \mathrm{~kg} \mathrm{~N}^{-1}$.

In that way, this approach addressed two issues highlighted by Asseng et al. (2012), who suggested that (i) the realistic risk behavior seen in farmers' decision making and (ii) variations in input costs and wheat prices must be considered in agricultural management decisions.

\section{Conclusions}

This research sought to demonstrate the importance of environment-management interactions when investigating the optimal $\mathrm{N}$ management practices. Optimizing nitrogen management based solely on field experiments is very difficult. Moreover, in-season $\mathrm{N}$ optimization requires the ability to adapt to withinseason climatic patterns and to the related stresses that will impact crop growth and nutrient uptake. Thus, simulation modeling provides a powerful means of integrating all the factors that impact growth and markedly extending the interpretation that is possible based on limited experimental studies. However, to be used as a formal decision support system, a crop model must to be embedded in the appropriate approach, which, in this case, relies on three specific characteristics: the ability to (i) consider real-time climate monitoring, (ii) to simulate the agro-environmental variable up to the end of the season, and (iii) to efficiently identify optimal management solutions. This research was an effort in this direction.

Special attention was paid to develop the research in a context of the agronomic, economic, and environmental pressures that may affect farmers. A calibrated soil-crop model (STICS) was coupled with a weather generator (LARS-WG) to simulate the expected yields and perform probability risk assessment. A complete methodology and an optimized algorithm were developed to automatically predict the date of fertilizer application and tactically optimize $\mathrm{N}$ management in response to simultaneous real-time climate monitoring and a probabilistic approach to future weather scenarios. Specific decision rules were developed to determine the optimal $\mathrm{N}$ practices on the basis of economic and environmental criteria.

In Belgium, the most typical $\mathrm{N}$ management consists of applying $60-60-60 \mathrm{~kg} \mathrm{~N} \mathrm{ha}^{-1}$ at the tiller (ZS 23), stem extension (ZS 30) and flag-leaf stages (ZS 39). For reasons mainly linked to the physiology of grain yield elaboration, this research focused on the optimization of the third application.

The results suggested that there is a large potential to maximize farmers' revenues and minimize environmental pressure through the selection of an optimal $\mathrm{N}$ rate. The analysis showed that past growing conditions between the sowing and flag-leaf stages markedly impacted crop growth and subsequent grain filling, limiting yield potential. This greatly impacted the crop efficiency in terms of taking advantage of the third $\mathrm{N}$ application. Therefore, the climatic records, when used as future projections, had a greater impact on the simulated yields than the $\mathrm{N}$ fraction applied at ZS 39 alone.

The retro-application of the tactical approach to the 33 years of data stored in the climatic database showed important variability in terms of the optimal $\mathrm{N}$ rate and consequent yields, revenues, and leaching potential. Our results suggest that it is not economically and certainly not environmentally sustainable to systematically apply the current farmers' $\mathrm{N}$ practice of $60-60-60 \mathrm{~kg} \mathrm{~N}^{-1}$ application. Most of the time, the third $\mathrm{N}$ application should be reduced due to the climatic pattern encountered by the plant between sowing and ZS 39 of the ongoing season, as well as the market prices of crop and fertilizer.
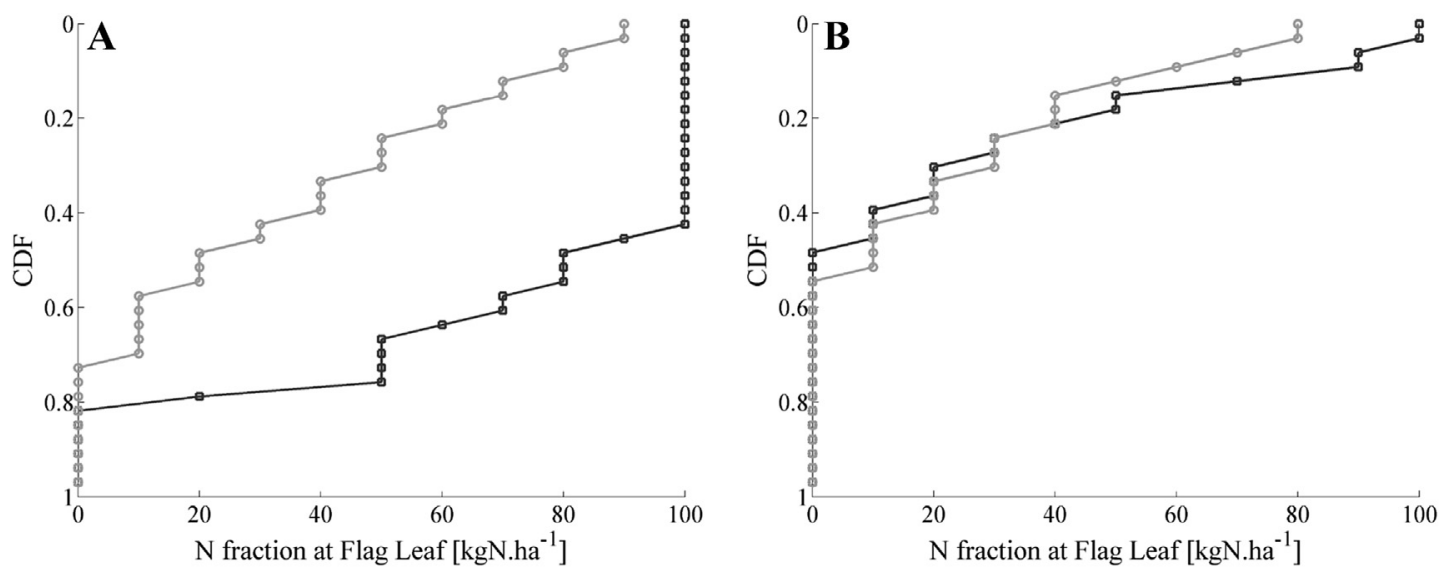

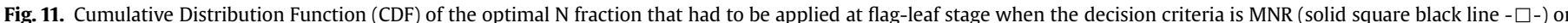

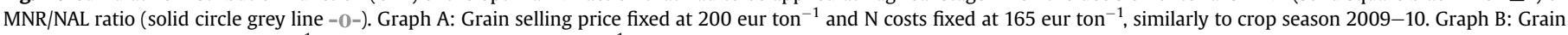
selling price fixed at 130 eur ton ${ }^{-1}$ and $\mathrm{N}$ costs fixed at 300 eur ton ${ }^{-1}$, similarly to crop season 2013-14. 
This paper puts effort in describing fully and properly the approach and supporting its validity by significant results. Further research perspectives should be to compare the results obtained with different crop models, ideally extending the approach to a model-ensemble exercise.

In summary, the environment-management interaction analysis has shown that using a well-calibrated crop growth model embedded in the appropriate approach is a powerful tool to use in exploring the impact of variable $\mathrm{N}$ practices and optimize $\mathrm{N}$ management.

\section{Acknowledgments}

The authors would like to thank the Service Public de Wallonie (SPW, DGARNE - DGO-3 - Grants D31-1203, D31-1244 and D311303) for its financial support for the project entitled 'Suivi en temps réel de l'environnement dune parcelle agricole par un réseau de microcapteurs en vue d'optimiser l'apport en engrais azotés'. They also wish to thank the OptimiSTICS team for allowing them to use the Matlab running code of the STICS model, and they are very grateful to CRA-W, especially the Systèmes agraires, Territoire et Technologies de l'Information unit, for giving them access to the Ernage station climatic database. They finally want to thank the MACSUR and AgMIP projects where the authors shared experiences.

\section{References}

Asseng, S., McIntosh, P.C., Wang, G., Khimashia, N., 2012. Optimal N fertiliser management based on a seasonal forecast. Eur. J. Agron. 38 (0), 66-73.

Asseng, S., Turner, N., 2007. Modelling genotype x environment x management interactions to improve yield, water use efficiency and grain protein in wheat. In: Spiertz, J.H.J., Struik, P.C., van Laar, H.H. (Eds.), Scale and Complexity in Plant Systems Research: Gene-plant-crop Relations. Springer, Netherlands, pp. 93-104.

Basso, B., Fiorentino, C., Cammarano, D., Cafiero, G., Dardanelli, J., 2012a. Analysis of rainfall distribution on spatial and temporal patterns of wheat yield in Mediterranean environment. Eur. J. Agron. 41 (0), 52-65.

Basso, B., Ritchie, J.T., 2005. Impact of animal manure, compost and inorganic fertilizer on nitrate leaching and yield in a six-year maize alfalfa rotation. Agric Ecosyst. Environ. 108, 329-341.

Basso, B., Ritchie, J.T., Cammarano, D., Sartori, L., 2011a. A strategic and tactical management approach to select optimal $\mathrm{N}$ fertilizer rates for wheat in a spatially variable field. Eur. J. Agron. 35 (4), 215-222.

Basso, B. Sartori, L., Bertocco, M., Cammarano, D., Martin, E.C., Grace, P.R., 2011b. Economic and environmental evaluation of site-specific tillage in a maize crop in NE Italy. Eur. J. Agron. 35 (2), 83-92.

Basso, B., Sartori, L., Cammarano, D., Fiorentino, C., Grace, P.R., Fountas, S. Sorensen, C.A., 2012b. Environmental and economic evaluation of $\mathrm{N}$ fertilizer rates in a maize crop in Italy: a spatial and temporal analysis using crop models. Biosyst. Eng. 113 (2), 103-111.

Beaudoin, N., Launay, M., Sauboua, E., Ponsardin, G., Mary, B., 2008. Evaluation of the soil crop model STICS over 8 years against the 'on farm' database of Bruyères catchment. Eur. J. Agron. 29, 46-57.

Bergez, J.E., Raynal, H., Launay, M., Beaudoin, N., Casellas, E., Caubel, J., Chabrier, P. Coucheney, E., Dury, J., Garcia de Cortazar-Atauri, I., Justes, E., Mary, B., Ripoche, D., Ruget, F., 2014. Evolution of the STICS crop model to tackle new environmental issues: new formalisms and integration in the modelling and simulation platform RECORD. Environ. Model. Softw. 62, 370-384.

Brisson, N., Gary, C., Justes, E., Roche, R., Mary, B., Ripoche, D., Zimmer, D., Sierra, J., Bertuzzi, P., Burger, P., Bussière, F., Cabidoche, Y.M., Cellier, P., Debaeke, P. Gaudillère, J.P., Hénault, C., Maraux, F., Seguin, B., Sinoquet, H., 2003. An overview of the crop model stics. Eur. J. Agron. 18 (3-4), 309-332.

Brisson, N., Launay, M., Mary, B., Beaudoin, N., 2009. Conceptual Basis, Formalisations and Parameterization of the STICS Crop Model. Editions Quae, Collection Update Sciences and Technologies.

Brisson, N., Mary, B., Ripoche, D., Jeuffroy, M.H., Ruget, F., Nicoullaud, B., Gate, P., Devienne-Barret, F., Antonioletti, R., Durr, C., Richard, G., Beaudoin, N., Recous, S., Tayot, X., Plenet, D., Cellier, P., Machet, J.-M., Meynard, J.M. Delécolle, R., 1998. STICS: a generic model for the simulation of crops and their water and nitrogen balances. I. Theory and parameterization applied to wheat and corn. Agronomie 18 (5-6), 311-346.

Brisson, N., Ruget, F., Gate, P., Lorgeau, J., Nicoulaud, B., Tayo, X., Plenet, D., Jeuffroy, M.H., Bouthier, A., Ripoche, D., Mary, B., Justes, E., 2002. STICS: a generic model for simulating crops and their water and nitrogen balances. II Model validation for wheat and maize. Agronomie 22, 69-82.
Brown, H., Huth, N., Holzworth, D., Teixeira, E., Zyskowski, R., Hargreaves, J., Moot, D., 2014. Plant modelling framework: software for building and running crop models on the APSIM platform. Environ. Model. Softw. 62, 385-398.

Casadebaig, P., Debaeke, P., 2011. Using a crop model to assess genotypeenvironment interactions in multi-environment trials. In: Presented at Systems Approaches to Crop Improvement, Aspects of Applied Biology (107). Warwick, GBR: AAB - Association of Applied Biologists. Rothamsted Research, Harpenden, GBR.

Chenu, K., Cooper, M., Hammer, G., Mathews, K., Dreccer, M., Chapman, S., 2011. Environment characterization as an aid to wheat improvement: interpreting genotype-environment interactions by modelling water-deficit patterns in north-eastern Australia. J. Exp. Bot. 62, 1743-1755.

Constantin, J., Beaudoin, N., Launay, M., Duval, J., Mary, B., 2012. Long-term nitrogen dynamics in various catch crop scenarios: test and simulations with STICS model in a temperate climate. Agric. Ecosyst. Environ. 147 (0), 36-46.

Coucheney, E., Buis, S., Launay, M., Constantin, J., Mary, B., García de CortázarAtauri, I., Ripoche, D., Beaudoin, N., Ruget, F., Andrianarisoa, K.S., Le Bas, C., Justes, E., Léonard, J., 2015. Accuracy, robustness and behavior of the STICS soil-crop model for plant, water and nitrogen outputs: evaluation over a wide range of agro-environmental conditions in France. Environ. Model. Softw. 64, $177-190$.

Day, R.H., 1965. Probability distributions of field crop yields. J. Farm. Econ. 47 (3), 713-741.

Dumont, B., Basso, B., Bodson, B., Destain, J., Destain, M., 2015a. Climatic risk assessment to improve nitrogen fertilisation recommendations: a strategic crop model-based approach. Eur. J. Agron. 65, 10-17.

Dumont, B., Basso, B., Ferrandis, S., Leemans, V., Bodson, B., Destain, J., Destain, M., 2015b. A comparison of within-season yield prediction algorithms based on crop model behaviour analysis. Agric. Forest Meteorol. 204, 10-21.

Dumont, B., Basso, B., Leemans, V., Bodson, B., Destain, J., Destain, M., 2014a. Systematic analysis of site-specific yield distributions resulting from nitrogen management and climatic variability interactions. Precis. Agric. 16 (4), 361-384.

Dumont, B., Leemans, V., Mansouri, M., Bodson, B., Destain, J., Destain, M., 2014b. Parameter optimisation of the STICS crop model, with an accelerated formal MCMC approach. Environ. Model. Softw. 52, 121-135.

Dumont, B., Leemans, V., Ferrandis, S., Vancutsem, F., Bodson, B., Destain, J., Destain, M., 2014c. Assessing the potential to predict wheat yields supplying the future by a daily mean climatic database. Precis. Agric. 15 (3), 255-272.

Dumont, B., Basso, B., Leemans, V., Bodson, B., Destain, J.P., Destain, M.F., 2013. Yield variability linked to climate uncertainty and nitrogen fertilisation. In: Stafford, J. (Ed.), Precision Agriculture '13. Proceedings of the 9th European Conference on Precision Agriculture. Wageningen Academic Publishers, The Netherlands, pp. 427-434.

EC-Council Directive, 1991. Council Directive 91/676/EEC Concerning the Protection of Waters Against Pollution Caused by Nitrates from Agricultural Sources.

Ewert, F., van Ittersum, M.K., Heckelei, T., Therond, O., Bezlepkina, I., Andersen, E., 2011. Scale changes and model linking methods for integrated assessment of agri-environmental systems. Agric. Ecosyst. Environ. 142 (1-2), 6-17.

Hoogeboom, G.J., White, J.W., Messina, C.D., 2004. From genome to crop: integration through simulation modelling. Field Crop Res. 90, 145-163.

Houlès, V., Mary, B., Guérif, M., Makowski, D., Justes, E., 2004. Evaluation of the ability of the crop model STICS to recommend nitrogen fertilisation rates according to agro-environmental criteria. Agronomie 24 (6-7), 339-349.

Kyveryga, P.M., Caragea, P.C., Kaiser, M.S., Blackmer, T.M., 2013. Predicting risk from reducing nitrogen fertilization using hierarchical models and on-farm data. Agron. J. 105 (1), 85-94.

Lawless, C., Semenov, M.A., 2005. Assessing lead-time for predicting wheat growth using a crop simulation model. Agric. Forest Meteorol. 135 (1-4), 302-313.

Makowski, D., Wallach, D., Meynard, J.-M., 2001. Statistical methods for predicting responses to applied nitrogen and calculating optimal nitrogen rates. Agron. J. 93 (3), 531-539.

Martre, P., Semenov, M., Jamieson, P., 2007. Simulation analysis of physiological traits to improve yield, nitrogen use efficiency and grain protein concentration in wheat. In: Spiertz, J.H.J., Struik, P.C., van Laar, H.H. (Eds.), Scale and Complexity in Plant Systems Research: Gene-plant-crop Relations. Springer, Netherlands, pp. 181-201.

Palosuo, T., Kersebaum, K.C., Angulo, C., Hlavinka, P., Moriondo, M., Olesen, J.E., Patil, R.H., Ruget, F., Rumbaur, C., Takáč, J., Trnka, M., Bindi, M., Çaldağ, B., Ewert, F., Ferrise, R., Mirschel, W., Saylan, L., Siška, B., Rötter, R., 2011. Simulation of winter wheat yield and its variability in different climates of Europe: a comparison of eight crop growth models. Eur. J. Agron. 35 (3), 103-114.

Penman, H.L., 1948. Natural evaporation from open water, bare soil and grass. Proc. R. Soc. Lond. A 194, 120-145.

Racsko, P., Szeidl, L., Semenov, M., 1991. A serial approach to local stochastic weather models. Ecol. Modell. 57 (1-2), 27-41.

Riha, S.J., Wilks, D.S., Simoens, P., 1996. Impact of temperature and precipitation variability on crop model predictions. Clim. Change 32 (3), 293-311.

Semenov, M., Porter, J., 1995. Climatic variability and the modelling of crop yields, Agric. Forest Meteorol. 73 (3-4), 265-283.

Semenov, M.A., Barrow, E.M., 1997. Use of a stochastic weather generator in the development of climate change scenarios. Clim. Change 35 (4), 397-414.

Semenov, M.A., Barrow, E.M., 2002. LARS-WG - a Stochastic Weather Generator for Use in Climate Impact Studies. User manual, version 3.0, August 2002. Tech. rep., Rothamsted Research, Harpenden, Hertfordshire, AL5 2JQ UK.

Semenov, M.A., Halford, N.G., 2009. Identifying target traits and molecular 
mechanisms for wheat breeding under a changing climate. J. Exp. Bot. 60 (10), 2791-2804.

Semenov, M.A., Jamieson, P.D., Martre, P., 2007. Deconvoluting nitrogen use efficiency in wheat: a simulation study. Eur. J. Agron. 26 (3), 283-294.

Semenov, M.A., Martre, P., Jamieson, P.D., 2009. Quantifying effects of simple wheat traits on yield in water-limited environments using a modelling approach. Agric. Forest Meteorol. 149 (6-7), 1095-1104.

Shuttleworth, W.J., Wallace, J.S., 1985. Evaporation from sparse crops-an energy combination theory. Quart. J. R. Meteor. Soc. 111 (469), 839-855.

Sinclair, T.R., Seligman, N.A.G., 1996. Crop modeling: from infancy to maturity. Agron. J. 88 (5), 698-704.

Talbot, G., Roux, S., Graves, A., Dupraz, C., Marrou, H., Wery, J., 2014. Relative yield decomposition: a method for understanding the behaviour of complex crop models. Environ. Model. Softw. 51, 136-148.

Vandenberghe, C., Marcoen, J., Sohier, C., Degre, A., Hendrickx, C., Paulus, P., 2011.
Monitoring networks and modelling systems for assessing effectiveness of the EU nitrates directive action programmes: approach by the Walloon region Belgium). In: Results of the Second International Workshop, 10-11 June 2009.

Vrugt, J.A., Braak, C.J.F.T., Diks, C.G.H., Robinson, B.A., Hyman, J.M., Higdon, D., 2009 Accelerating Markov chain Monte Carlo simulation by differential evolution with self-adaptive randomized subspace sampling. Int. J. Nonlinear Sci. Numer. Simul. 10 (3), 273-290.

Wallach, D., Buis, S., Lechapentier, P., Bourges, J., Clastre, P., Launay, M., Bergez, J.E., Gueriff, M. Soudais, J., Justes, E., 2011. A package of parameter estimation methods and implementation for the STICS crop-soil model. Environ. Model. Softw. 26, 386-394.

Weiss, A., Wilhelm, W., 2006. The circuitous path to the comparison of simulated values from crop models with field observations. J. Agric. Sci. 144, 475-488.

Zadoks, J.C., Chang, T.T., Konzak, C.F., 1974. A decimal code for the growth stages of cereals. Weed Res 14, 415-421. 